\title{
Parameter Design for Viscous Dampers to Near-fault Cable-stayed Bridge Based on Equivalent Damping Ratio
}

\author{
Yongfu Huang ${ }^{\mathrm{a}}$, Yan $\mathrm{Xu}{ }^{\mathrm{b}}$, Jianzhong $\mathrm{Li}^{\mathrm{c}}$ \\ Tongji University State key laboratory for disaster reduction in Civil Engineering, Shanghai 200092, \\ China \\ a983588286@qq.com, byanxu@tongji.edu.cn, clijianzh@tongji.edu.cn
}

Keywords: viscous dampers, equivalent damping ratio, equivalent linearization, cable-stayed bridge, near-fault ground motion.

\begin{abstract}
In order to investigate the simplified design method for damper installed on cable-stayed bridge in near-fault zones, this paper proposed two-particle model for cable-stayed bridge and established the differential equations of motion. Parameter design formula for linear viscous damper is derived based on the concept of equivalent damping ratio, parameter design formula for nonlinear viscous damper is also deducted by equivalent linearization method. In the end, a single tower cable-stayed bridge is cited to verify accuracy of the formulations.
\end{abstract}

\section{Introduction}

After the Loma Prieta earthquake, Northridge earthquake, Izmit earthquake, Kobe earthquake and Chi-Chi earthquake, many disaster investigations showed that destruction of buildings in near-fault areas are more severe than the areas far away from fault ${ }^{[1]}$ to [3], researches found the presence of strong seismic pulse in near-fault earthquake recordings, and that large velocity pulse can cause significant seismic response to structure several times higher than that of ordinary earthquake ${ }^{[4]}$, which is the main reason for collapse or damage of bridge in near-fault areas.

With the planning and construction of the transportation network, cable-stayed bridges are inevitably to be built in the vicinity of the fault. Cable-stayed bridge are mostly adopted the floating system, which has long natural period with the advantages of seismic energy dissipation. On the other hand, there is no restraint device between tower and girder in floating system, therefore the girder is floating with a large seismic displacement in longitudinal direction, resulting in expansion joints damages, girder collision and falling off. While, viscous damper is used widely as a displacement-limit device, it has the effect of energy dissipation, increasing the capacity of seismic and wind resistance for bridge, and controlling the displacement of girder. The mechanical model of hydraulic viscous dampers can be expressed by Equation 1:

$$
F=C \cdot \operatorname{sgn}(v) \cdot|v|^{\alpha}
$$

Where $F$ is the damper force, $C$ is the damping coefficient determined by experiment, $\alpha$ is the damping exponent, whose value is generally in the range of $0.2 \sim 1.0$ in engineering, $v$ is relative velocity of the damper, sgn is the sign function. Determining reasonable damper parameters needs repeat calculation by finite element analysis, which is clearly unrealistic in the preliminary design stage of bridge engineering. Due to the lack of parameter design and research on cable-stayed bridge with viscous damper, this paper proposed a design formulation for viscous damper based on the concept of equivalent damping ratio, and an example is made to validate this method.

\section{Formulation derivation}

Firstly the concept of equivalent damping ratio is introduced. If the supplemental vicious damper on structure is considerd as additional damping, then the equivalent damping ratio is consist of the structural inherent damping ratio and the additional damping ratio (Equation 2), $\xi, \xi_{0}, \xi_{d}$ represent the system equivalent damping ratio, structural inherent damping ratio and additional damping ratio (related to viscous dampers), respectively. Most domestic and international studies suggest that 
structural damping ratio is basically fixed in elastic state, for example, $5 \%$ for concrete arch bridge, $3 \%$ for cable-stayed bridge and $2 \%$ for suspension bridge ${ }^{[5]}$. For cable-stayed bridge with supplemental viscous damper, structural damping ratio is $3 \%$, then additional damping ratio can be obtained according to the target equivalent damping ratio of the system, thus the design formula for parameters of viscous damper can be solved.

$$
\xi=\xi_{0}+\xi_{\mathrm{d}}
$$

Parameter design formulation for linear viscous damper. When cable-stayed bridge is installed with viscous dampers, the structure presents significant feature of two-particle system because of the interaction between the girder and the tower (Fig.1). In order to establish a relationship between damper parameters and target equivalent damping ratio of the system, a simplified two degree of freedom model for cable-stayed bridge is proposed. By using the equivalent modal method $^{[6]}$, many scholars have studied the simplification of bridge tower ${ }^{[7]-[8]}$, the tower of cable-stayed bridge can be simplified to a single degree of freedom model with no distributional mass but concentrate mass at the top, the girder is regarded as another independent particle. According to the calculation diagram of cable-stayed bridge, the differential equations of motion of two-particle system in longitudinal direction is written as follows:
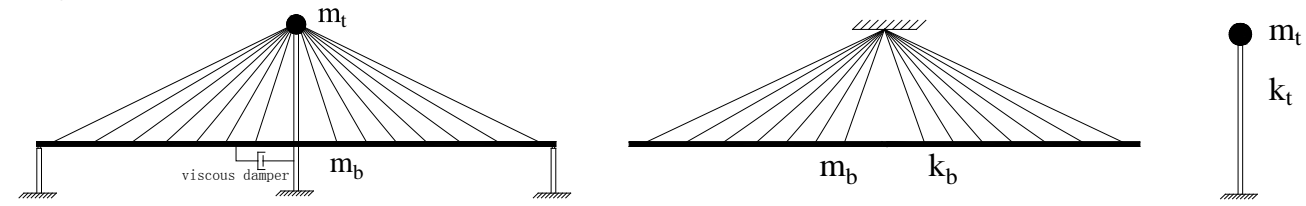

Fig.1. The cable-stayed bridge two particle calculation diagram in Figure

$$
\left[\begin{array}{cc}
m_{b} & 0 \\
0 & m_{t}
\end{array}\right]\left\{\begin{array}{l}
\ddot{u}_{b} \\
\ddot{u}_{t}
\end{array}\right\}+\left[\begin{array}{cc}
c_{b}+c_{d} & -c_{b}-c_{d} \\
-c_{b}-c_{d} & c_{b}+c_{d}+\delta c_{t}
\end{array}\right]\left\{\begin{array}{l}
\dot{u}_{b} \\
\dot{u}_{t}
\end{array}\right\}+\left[\begin{array}{cc}
k_{b} & -k_{b} \\
-k_{b} & k_{b}+k_{t}
\end{array}\right]\left\{\begin{array}{l}
u_{b} \\
u_{t}
\end{array}\right\}=-\left[\begin{array}{cc}
m_{b} & 0 \\
0 & m_{t}
\end{array}\right]\left\{\begin{array}{l}
1 \\
1
\end{array}\right\} \ddot{u}_{g}
$$

Where $\ddot{u}_{b}, \dot{u}_{b}, u_{b}$ are respectively acceleration, velocity, displacement of girder relative to the ground. $\ddot{u}_{t}, \dot{u}_{t}, u_{t}$ are respectively acceleration, velocity, displacement of top tower relative to the ground. $\ddot{u}_{g}$ is the acceleration of ground motion. $m_{b}$ and $m_{t}$, the mass of tower and girder. $k_{b}$ and $k_{t}$, longitudinal rigidity of girder and tower. $c_{b}$ and $c_{t}$, damping of girder and tower, $c_{d}$ is the damping efficient of viscous damper. $\delta$ is the ratio of displacement of tower at the top and the position of damper. By solving the characteristic equation (Equation 4), the natural frequencies and mode shapes of cable-stayed bridge are obtained as follows:

$$
\begin{aligned}
& \mid[K]-\omega_{n}^{2}[M]=0 \quad n=1,2 \\
& \omega_{1,2}^{2}=\frac{1-\gamma}{R_{S}} \frac{\left[1+R_{S} /(1-\gamma)\right] \mp\left[\left(1+R_{S} /(1-\gamma)\right)^{2}-4 \gamma R_{S} /(1-\gamma)\right]^{1 / 2}}{2 \gamma} \omega_{b}^{2} \\
& \phi_{1}=\left(\begin{array}{c}
1 \\
1-\alpha_{1}
\end{array}\right) \quad \phi_{1}=\left(\begin{array}{c}
1 \\
1-\alpha_{2}
\end{array}\right)
\end{aligned}
$$

Where, $\omega_{1}, \omega_{2}$ are the vibration frequencies of the two masses. $\phi_{1}, \phi_{2}$ are respectively the modes of the two masses. The expression of other parameters are listed as follows:

$$
\begin{aligned}
& \omega_{b}^{2}=k_{b} / m_{b}, \quad \omega_{t}^{2}=k_{t} /\left(m_{b}+m_{t}\right), \quad \gamma=m_{t} /\left(m_{b}+m_{t}\right) \\
& R_{S}=k_{b} / k_{t}, \quad \alpha_{1}=\omega_{1}^{2} / \omega_{b}^{2}, \quad \alpha_{2}=\omega_{2}^{2} / \omega_{b}^{2}
\end{aligned}
$$

According to the concept of matrix diagonalization, the damping matrix can be considered a diagonal matrix in modal coordinate, ignoring the impact of its off -diagonal elements ${ }^{[9]}$. The generalized mass matrix and the generalized damping matrix is written as follows:

$$
\begin{aligned}
& {\left[M^{*}\right]=[\phi]^{T}[M][\phi]=\left[\begin{array}{ll}
m_{11}^{*} & m_{12}^{*} \\
m_{21}^{*} & m_{22}^{*}
\end{array}\right]=\left[\begin{array}{cc}
m_{b}+\left(1-\alpha_{1}\right)^{2} m_{t} & 0 \\
0 & m_{b}+\left(1-\alpha_{2}\right)^{2} m_{t}
\end{array}\right]} \\
& {\left[C^{*}\right]=[\phi]^{T}[C][\phi]=\left[\begin{array}{ll}
c_{11}^{*} & c_{12}^{*} \\
c_{21}^{*} & c_{22}^{*}
\end{array}\right]}
\end{aligned}
$$




$$
\begin{aligned}
& c_{11}^{*}=\left(c_{b}+c_{d}\right)-2\left(1-\alpha_{1}\right)\left(c_{b}+\delta c_{d}\right)+\left(1-\alpha_{1}\right)^{2}\left(c_{b}+c_{t}+\delta c_{d}\right) \\
& c_{22}^{*}=\left(c_{b}+c_{d}\right)-2\left(1-\alpha_{2}\right)\left(c_{b}+\delta c_{d}\right)+\left(1-\alpha_{2}\right)^{2}\left(c_{b}+c_{t}+\delta c_{d}\right)
\end{aligned}
$$

So the equivalent modal damping ratio are obtained by:

$$
\xi_{1}=\frac{c_{11}^{*}}{2 m_{11}^{*} \omega_{1}}=\frac{\left(c_{b}+c_{d}\right)-2\left(1-\alpha_{1}\right)\left(c_{b}+\delta c_{d}\right)+\left(1-\alpha_{1}\right)^{2}\left(c_{b}+c_{t}+\delta c_{d}\right)}{2 \omega_{1}\left[m_{b}+\left(1-\alpha_{1}\right)^{2} m_{t}\right]}
$$

Substituting $c_{b}=2 m_{b} \xi_{b} \omega_{b}, \quad c_{d}=2 m_{b} \xi_{d} \omega_{b}, c_{t}=2\left(m_{b}+m_{t}\right) \xi_{t} \omega_{t}$ into the Equation 5, the equivalent modal damping ratio is expressed as:

$$
\xi_{1}=\frac{\xi_{b} \alpha_{1}^{2}(1-\gamma)+\xi_{d}\left(1-\delta+\alpha_{1}^{2} \delta\right)(1-\gamma)+\xi_{t}\left(1-\alpha_{1}\right)^{2} \sqrt{(1-\gamma) / R_{S}}}{\sqrt{\alpha_{1}}\left[(1-\gamma)+\left(1-\alpha_{1}\right)^{2} \gamma\right]}
$$

The target equivalent damping ratio is considered to depend on the first modal damping ratio approximately, ie. $\xi_{e}=\xi_{1}$. Therefore the additional damping ratio contributed by viscous damper is:

$$
\xi_{d}=\frac{\xi_{e} \sqrt{\alpha_{1}}\left[(1-\gamma)+\left(1-\alpha_{1}\right)^{2} \gamma\right]-\xi_{b} \alpha_{1}^{2}(1-\gamma)-\xi_{t}\left(1-\alpha_{1}\right)^{2} \sqrt{(1-\gamma) / R_{s}}}{\left(1-\delta+\alpha_{1}^{2} \delta\right)(1-\gamma)}
$$

When cable-stayed bridge is installed with linear viscous damper, the damping coefficient $c_{d}$ is expressed as:

$$
c_{d}=2 m_{b} \xi_{d} \omega_{b}=2 m_{b} \omega_{b} \frac{\xi_{e} \sqrt{\alpha_{1}}\left[(1-\gamma)+\left(1-\alpha_{1}\right)^{2} \gamma\right]-\xi_{b} \alpha_{1}^{2}(1-\gamma)-\xi_{t}\left(1-\alpha_{1}\right)^{2} \sqrt{(1-\gamma) / R_{S}}}{\left(1-\delta+\alpha_{1}^{2} \delta\right)(1-\gamma)}
$$

Parameter design formulation for nonlinear viscous damper. When the cable-stayed bridge is installed with nonlinear viscous damper, the differential equations of motion of two-particle system (Equation 3) is nonlinear, so analytic expressions will not be obtained. And step by step integration in time history analysis will bring a great deal of trouble to the simplification of calculation. However, equivalent linearization method makes it possible to equal non-linear viscous damper into linear viscous damper by the equal energy dissipation principle ${ }^{[10]}$. Equal energy dissipation principle means that under an excitation of harmonic load $u_{d}=u_{0} \sin (\omega t)$, nonlinear viscous damper and linear viscous damper dissipates the same energy in one cycle of vibration.

Energy dissipation of linear viscous damper in one cycle is:

$$
E_{I}=\int f F_{D} d u=\int_{0}^{2 \pi / \omega} C_{e q} \cdot \dot{u}^{2} d t=\pi C_{e q} \omega u_{0}^{2}
$$

Energy dissipation of nonlinear viscous damper in one cycle is:

$$
E_{f}=\llbracket F_{D} d u=\int_{0}^{2 \pi / \omega} C \cdot \dot{u}^{\alpha+1} d t=2^{\alpha+2} C u_{0}^{\alpha+1} \omega^{\alpha} \frac{\Gamma^{2}(\alpha / 2+1)}{\Gamma(\alpha+2)}
$$

Where $\omega$ is the frequency of excitation, gamma function $\Gamma$ is the extension of factorial in real set, $\Gamma(n)=(n-1)$ !. Order $E_{I}=E_{f}$, the expression of equivalent linear damping coefficient is obtained:

$$
\begin{aligned}
& C_{e q}=\frac{2^{\alpha+2}}{\pi} C u_{0}^{\alpha-1} \omega^{\alpha-1} \frac{\Gamma^{2}(\alpha / 2+1)}{\Gamma(\alpha+2)}=\frac{C u_{0}^{\alpha-1} \omega^{\alpha-1}}{\pi} \lambda \\
& \lambda=2^{\alpha+2} \frac{\Gamma^{2}(\alpha / 2+1)}{\Gamma(\alpha+2)}, u_{0}=D_{b}-\delta D_{t}=\left(1-\frac{\delta}{1+1 / R_{S}}\right) D_{b}
\end{aligned}
$$

Where $D_{b}$ is the maximum displacement of linear viscous dampers under seismic excitation. Substitute Equation 8 into parameter design formulation for linear viscous damper (Equation 6), thus parameter design formula for non-linear viscous damper is:

$$
c_{d}=\frac{2 \pi m_{b}}{\omega_{b}^{\alpha-2}\left[1-\delta R_{S} /\left(1+R_{S}\right)\right]^{\alpha-1} D_{b}^{\alpha-1} \lambda} \frac{\xi_{e} \sqrt{\alpha_{1}}\left[(1-\gamma)+\left(1-\alpha_{1}\right)^{2} \gamma\right]-\xi_{b} \alpha_{1}^{2}(1-\gamma)-\xi_{t}\left(1-\alpha_{1}\right)^{2} \sqrt{(1-\gamma) / R_{S}}}{\left(1-\delta+\alpha_{1}^{2} \delta\right)(1-\gamma)}
$$




\section{Numberical validation}

In order to verify the equivalent damping ratio method for cable-stayed bridge and the equivalent linearization method for nonlinear viscous damper, a single tower cable-stayed bridge of floating system is cited. The span arrangement of main bridge is $2 \times 230 \mathrm{~m}$, the concrete A-type tower is $150 \mathrm{~m}$ in hight with 17 pairs of stayed cables, and the girder is a steel box with a width of $37.3 \mathrm{~m}$. For simplicity, the bottom of tower and pier are fixed with the ground in the model, without considering the soil - structure interaction. Finite element model is built in the environment of Sap2000 (Fig.2). Then analysis is made to the following three systems of cable-stayed bridge: the first system is a model with a target equivalent damping ratio. The second system is a model installed with linear viscous damper, whose damping coefficient is calculated from the first system according to Equation 6. The third system is a model installed with nonlinear iscous damper, whose damping coefficient are obtained by equivalent linearization method according to Equation 8.

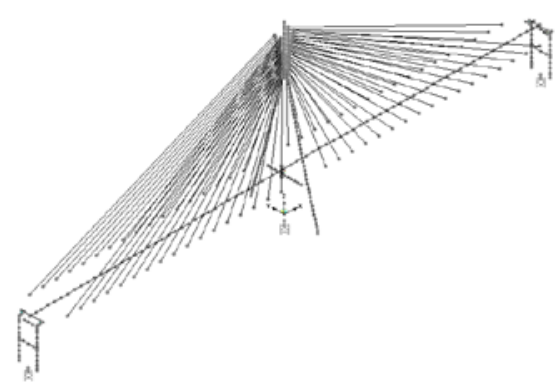

Fig 2. Finite element model of single tower cable-stayed bridge

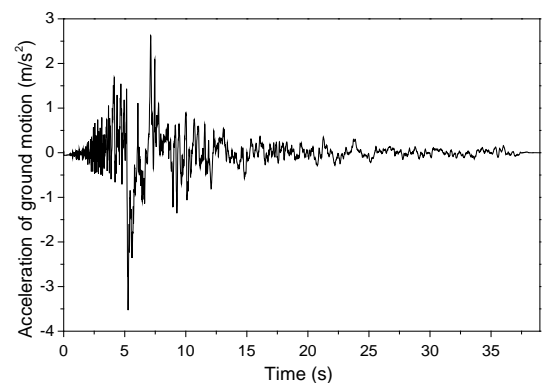

Fig 3. Near-fault seismic waves

Validation of equivalent damping ratio method. According to the existing design data, parameters of the single tower cable-stayed bridge: $m_{b}=11539 \mathrm{t}, m_{t}=7992 \mathrm{t}, k_{b}=44248 \mathrm{kN} / \mathrm{m}$, $k_{t}=30581 \mathrm{kN} / \mathrm{m}, \xi_{b}=\xi_{t}=3 \%$. According to Equation 6 , when the first system is assigned a target equivalent damping ratio of $15 \%$, the damping coefficient of linear viscous damper in the second system is $5077 \mathrm{kN} \cdot \mathrm{s} / \mathrm{m}$ correspondingly. Typical near-fault seismic record is selected (Fig.3) from the database website of Pacific Earthquake Engineering Research Center (http://peer.berkeley.edu/), through time history analysis to the first system and the second system, the displacement and acceleration history curves of the girder is drawed in Fig.4, while the moment and shear history curves at the bottom of tower is drawed in Fig.5.
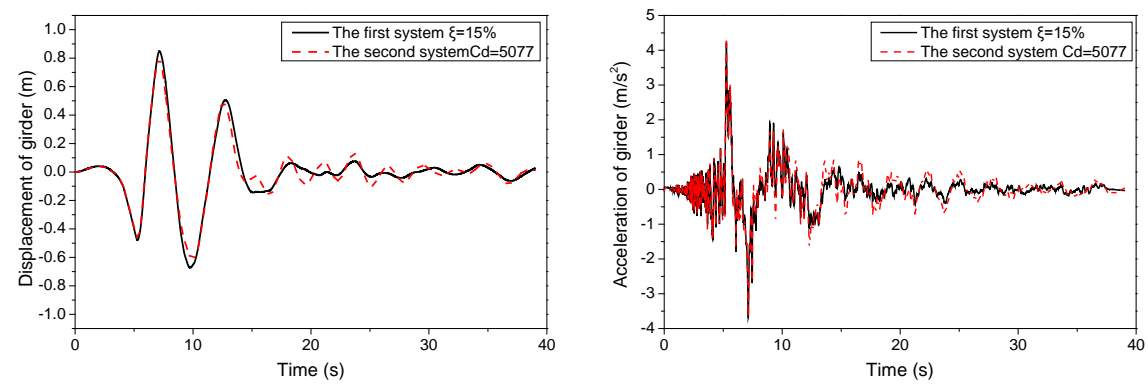

Fig. 4. displacement and acceleration history curves of girder under near-fault ground motion
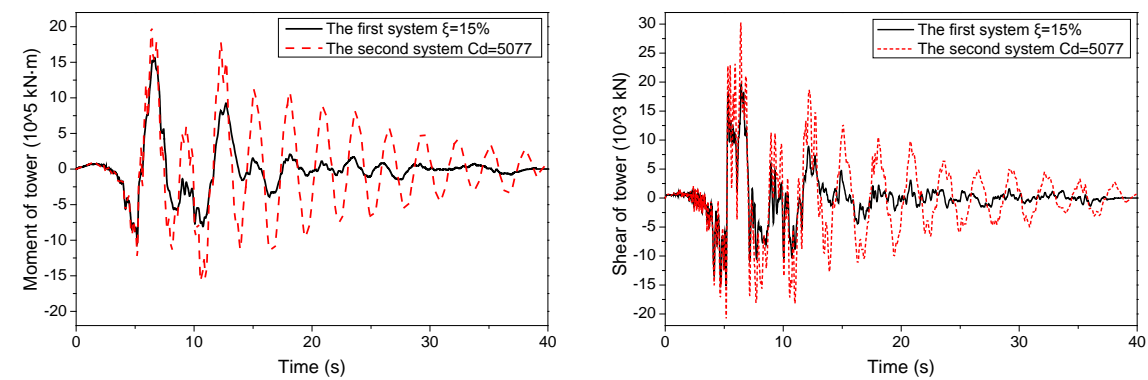

Fig. 5. moment and shear history curves at the bottom of tower under near-fault ground motion

It can be inferred from Fig. 4 that the peak and vibration frequency of displacement and acceleration in the first system and the second system are very close; Fig. 5 shows that the vibration 
frequency of moment and shear in the first system and the second system remain the same, although there are some differences in the peak (about 20\%), but it is acceptable in preliminary design stage. The results prove the accuracy of the design formulation for linear viscous damper (Equation 6 ), also shows that the equivalent damping ratio method has good applicability in single tower cable-stayed bridge.

Validation of equivalent linearization method for nonlinear viscous damper. Parameters of non-linear viscous dampers is related to the displacement $u_{0}$ (Equation 8) in the process of equivalent linearization, so the maximum seismic displacement of girder should be determined firstly, which equals to that of the first system approximately. $u_{0}=0.849 \mathrm{~m}, C_{e q}=5077 \mathrm{kN} \cdot \mathrm{s} / \mathrm{m}$, according to Equation 8, when the system equivalent damping ratio is $15 \%$, correspondly, the damping factor of non-linear viscous damper $C_{d}$ is $5739 \mathrm{kN} \cdot \mathrm{s} / \mathrm{m}$ with a damping exponent of 0.2 . Through time history analysis to the second system and the third system, the displacement and acceleration history curves of the girder is drawed in Fig. 6, while the moment and shear history curves at the bottom of tower is drawed in Fig. 7.
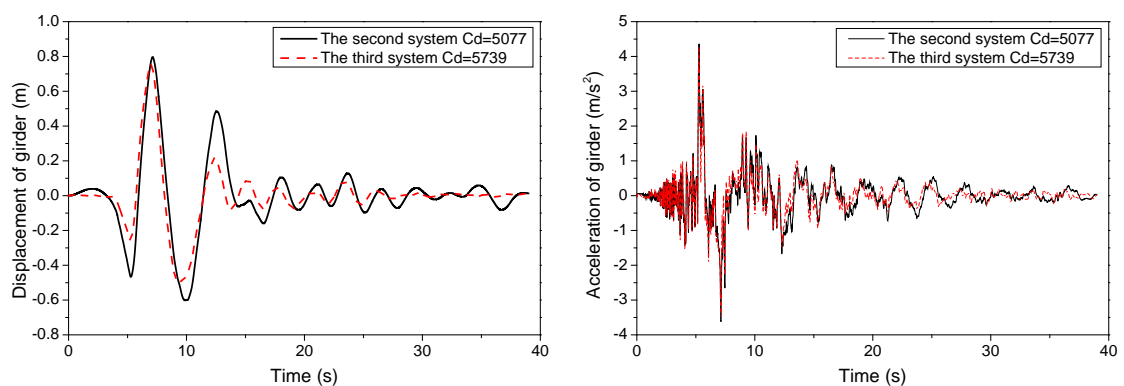

Fig. 6. displacement and acceleration history curves of girder under near-fault ground motion
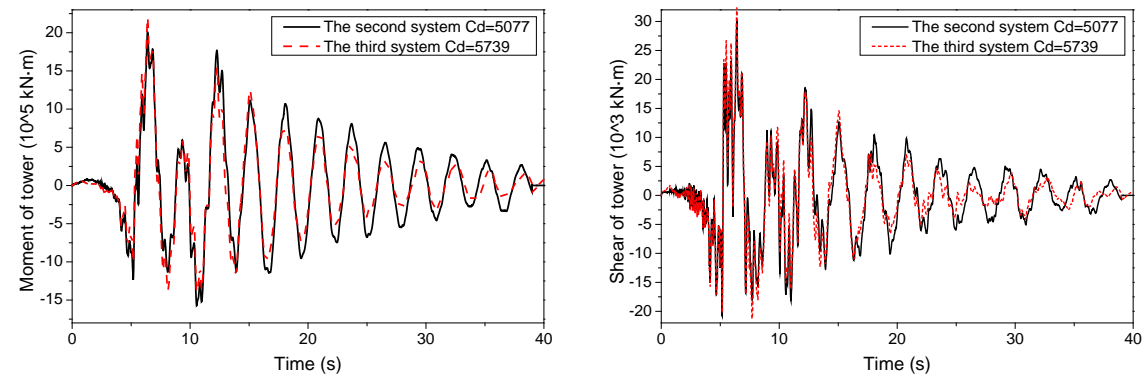

Fig. 7. moment and shear history curves at the bottom of tower under near-fault ground motion

The following conclusion can be summed from the charts above: the seismic response of the second system and the third system are extremely similar, although there exist minor differences in the displacement and acceleration of girder, and the moment and shear of tower. Therefore the process of equivalence from nonlinear viscous damper to linear viscous damper is successful, and the equivalent linearization method is proved quite correct.

\section{Summary}

For cable-stayed bridge of floating system in near-fault areas, this paper proposed a simplified model of two particle, and deduced parameter design formulations for linear viscous damper and nonlinear viscous damper based on the concept of equivalent damping ratio. Example is also made to verify the formulations. The results show that only reasonable error exist between the seismic response of the first system and the second system under near-fault seismic wave, which indicate that parameter design formulation for linear viscous damper is accurate. Seismic response of the second system keep close to that of the third system, proving the accuracy of the equivalent linearization method and the parameter design formulation for nonlinear viscous dampers. 


\section{References}

[1] Chioccarelli E, Iervolino I. Near - source seismic hazard and design scenarios [J] Earthquake engineering \& structural dynamics, 2013, 42 (4): 603-622.

[2] Champion C, Liel A. The effect of near-fault directivity on building seismic collapse risk [J] Earthquake Engineering \& Structural Dynamics, 2012, 41 (10):. 1391-1409.

[3] Adanur S, Altuni ş ik AC, Bayraktar A, et al. Comparison of near-fault and far-fault ground motion effects on geometrically nonlinear earthquake behavior of suspension bridges [J]. Natural hazards, 2012, 64 (1) : 593-614.

[4] Duan Xinzhi, Xu Yan, Li Jianzhong. Influence of near fault pulse effect on seismic response of long span bridge[J]. Journal of Shijiazhuang Railway University: Natural Science edition, 2011, 24(3): $1-6$.

[5] CJJ 166-2011. city bridge seismic design specifications [S].

[6] Anil K. Chopra Dynamics of structures:. Theory and applications to earthquake engineering [M] 3th ed America:.. Prentice-Hall, Inc, 2007

[7] Yan Haiquan, Wang Junjie. A tower model for seismic response prediction of floating cable-stayed bridge in longitudinal direction[J]. Earthquake engineering and Engineering Vibration, 2007, 27(4): 80-86.

[8] Yuan Wancheng, Yan Dong. Simplified calculational method of floating frequency for cable-stayed bridge[J]. Journal of Tongji University: Natural Science Edition, 2005, 33(11): 1423-1427.

[9] Veletsos AS, Ventura C E. Modal analysis of non - classically damped linear systems [J] Earthquake engineering \& structural dynamics, 1986, 14 (2): 217-243.

[10] Seleemah AA, Constantinou M C. Investigation of seismic response of buildings with linear and nonlinear fluid viscous dampers [M] // Technical Report NCEER. US National Center for Earthquake Engineering Research, 1997 (97-0004). 